\title{
Endogenous Auxin Profile in the Christmas Rose (Helleborus niger L.) Flower and Fruit: Free and Amide Conjugated IAA
}

\author{
Ana Brcko • Aleš Pěnčík • Volker Magnus • Tatjana Prebeg • Selma Mlinarić • \\ Jasenka Antunović · Hrvoje Lepeduš • Vera Cesar • Miroslav Strnad • \\ Jakub Rolčík • Branka Salopek-Sondi
}

\begin{abstract}
The reproductive development of the Christmas rose (Helleborus niger $\mathrm{L}$.) is characterized by an uncommon feature in the world of flowering plants: after fertilization the white perianth becomes green and photosynthetically active and persists during fruit development. In the flowers in which fertilization was prevented by emasculation (unfertilized) or entire reproductive organs were removed (depistillated), the elongation of the peduncle was reduced by $20-30 \%$, and
\end{abstract}

Ana Brcko and Aleš Pěnčík contributed equally to this work. Volker Magnus deceased in 2009. \section{Croatia \\ e-mail: abrcko@irb.hr \\ T. Prebeg \\ e-mail: tprebeg@agr.hr}

A. Brcko · V. Magnus · T. Prebeg · B. Salopek-Sondi Ruder Bošković Institute, Bijenička cesta 54, HR-10002 Zagreb,

A. Pěnčík · M. Strnad · J. Rolčík

Laboratory of Growth Regulators, Faculty of Science, Palacký

University and Institute of Experimental Botany AS CR,

Šlechtitelů 11, CZ-78371 Olomouc, Czech Republic

e-mail: alespencik@seznam.cz

M. Strnad

e-mail: miroslav.strnad@upol.cz

J. Rolčík

e-mail: jakub.rolcik@seznam.cz

\section{A. Pěnčík}

Department of Growth Regulators, Faculty of Science,

Centre of the Region Haná for Biotechnological and Agricultural

Research, Palacký University, Šlechtitelů 11,

CZ-78371 Olomouc, Czech Republic

S. Mlinarić · J. Antunović · V. Cesar

Department of Biology, University of J.J. Strossmayer, Trg

Ljudevita Gaja 6, HR-31000 Osijek, Croatia

e-mail: smlinaric@biologija.unios.hr vascular development, particularly lignin deposition in sclerenchyma, was arrested. Chlorophyll accumulation in sepals and their photosynthetic efficacy were up to $80 \%$ lower in comparison to fertilized flowers. Endogenous auxins were investigated in floral and fruit tissues and their potential roles in these processes are discussed. Analytical data of free indole-3-acetic acid, indole-3-ethanol (IEt), and seven amino acid conjugates were afforded by LC-MS/MS in floral tissues of fertilized as well as unfertilized and depistillated flowers. Among amino acid conjugates, novel ones with Val, Gly, and Phe were identified and quantified in the anthers, and in the

\author{
J. Antunović \\ e-mail: jantunovic@biologija.unios.hr \\ V. Cesar \\ e-mail: vcesarus@yahoo.com \\ H. Lepeduš \\ Agricultural Institute Osijek, Južno predgrađe 17, \\ HR-31000 Osijek, Croatia \\ e-mail: hlepedus@yahoo.com \\ T. Prebeg \\ Department of Ornamental Plants, Landscape Architecture and \\ History of Garden Art, Faculty of Agriculture, University \\ of Zagreb, Svetošimunska cesta 25, Zagreb, Croatia \\ B. Salopek-Sondi ( $\square)$ \\ Department of Molecular Biology, Ruđer Bošković Institute, \\ Bijenička cesta 54, HR-10002 Zagreb, Croatia \\ e-mail: salopek@irb.hr
}


fruit during development. Reproductive organs before fertilization followed by developing fruit at post-anthesis were the main source of auxin. Tissues of unfertilized and depistillated flowers accumulated significantly lower levels of auxin. Upon depistillation, auxin content in the peduncle and sepal was decreased to 4 and $45 \%$, respectively, in comparison to fruit-bearing flowers. This study suggests that auxin arising in developing fruit may participate, in part, in the coordination of the Christmas rose peduncle elongation and its vascular development.

Keywords Auxin · Indole-3-acetic acid · Amide conjugates - Christmas rose - Helleborus niger L. · Flower and fruit development · Perianth greening . Peduncle elongation · Vascular system

\section{Introduction}

Reproductive plant development, characterized by flowering and fruit formation, is a complex process that relies on careful timing and coordination of tissue development. The processes of flower and fruit development are highly mediated by the interplay of different plant hormones: auxins, cytokinins, gibberellins, abscisic acid (ABA), and ethylene (Ozga and Reinecke 2003; Finkelstein 2004; Srivastava and Handa 2005). Among them, auxins seem to trigger both the flower (Cheng and Zhao 2007) and the fruit developmental program (Alabadi and others 2009). In addition, auxins, primarily indole-3-acetic acid, appear to participate in the coordination of processes within and between floral organs during flower and fruit development, such as anther dehiscence, pollen maturation, gynoecium development, fertilization, fruit initiation, seed development, and fruit ripening (Sundberg and Østergaard 2009). Most of a plant's endogenous IAA is found not as a free and biologically active form, but rather as an ester linked to sugars or amide linked to amino acids and peptides. The proposed roles of these conjugates include storage, transport, compartmentalization, protection against degradation, and detoxification (Cohen and Bandurski 1982). Different plant species have distinct IAA conjugate profiles. In general, monocots accumulate mostly ester conjugates, whereas dicots preferably accumulate amide conjugates (see for review Bajguz and Piotrowska 2009; Ludwig-Müller 2011). Studies of the metabolism and the physiological role of auxins in reproductive development have been focused on commercially interesting species such as maize (Jensen and Bandurski 1994), pea (Magnus and others 1997), bean (Bialek and Cohen 1989), tomato (Epstein and others 2002), and wheat (Hess and others 2002). The largest body of information on auxin metabolism and its role in both vegetative and generative development resulted from research on the model plant Arabidopsis thaliana, particularly from the point of view of auxin identification and biochemistry to genetics and molecular biology (Östin and others 1998; Kowalczyk and Sandberg 2001; Ljung and others 2002; Aloni and others 2006; Østergaard 2009; Normanly 2010). In horticultural plants, auxin research was focused mostly on the growth and elongation of the peduncle, with the aim of improving flower traits according to market requirements. Early research dealt with the influence of floral organs on flower peduncle elongation. It was observed that removal of the flower or floral organs inhibits the elongation of the floral stalk or peduncle (Op den Kelder and others 1971; Hanks and Rees 1977). Treatment of emasculated or decapitated flowers with auxins (Edelbluth and Kaldewey 1976; Hanks and Rees 1977; De Munk 1979; Kohji and others 1979; Saniewski and De Munk 1981; Ohno and Kako 1991), as well as treatments of isolated stalk explants (Gabryszewska and Saniewski 1983), led to the conclusion that these plant hormones originating in anthers, gynoecium, or developing fruit are largely responsible for peduncle elongation. Identification of endogenous hormones during flowering in the tulip (Okubo and Uemoto 1985; Xu and others 2008) and barley (Wolbang and others 2004) confirm that diffusible auxins from floral organs, in the first place, and in coordination with gibberellins are responsible for stalk elongation. Despite these findings, systematic analyses of auxins during reproductive development are still missing, and the role of auxins in the coordination of floral organ development remains unclear.

Here we investigated flower and fruit development in the Christmas rose (Helleborus niger L.) during pre-anthesis, anthesis, and post-anthesis development. Christmas rose belongs to the genus Helleborus, which comprises about 20 perennial species with large, attractive flowers in various shades of purple, green, and white (Mathew 1989). Reproductive development of most of these plants is characterized by an interesting feature: they retain the perianth (formed by the sepals) until seed ripening with its color changing to green. Both the original species and hybrid cultivars are becoming increasingly popular as ornamentals (Burrell and Tyler 2006). H. niger is a species with an exceptionally long flowering period (2-6 months starting around Christmas) and particularly large flowers $(6-13 \mathrm{~cm})$, which change color from white to intensely green, both mixed with purple in sun-exposed locations (Salopek-Sondi and Magnus 2007). The greening process in the perianth and elongation of the peduncle are linked to the presence of developing fruit, which makes the fertilized Christmas rose flower an interesting model for the study of developmental aspects of sinksource interactions. It was previously shown that sepal greening and peduncle elongation of unfertilized or depistillated flowers were stalled at an early stage of development. The greening process could be stimulated to completion by 
treating the sepals with gibberellins and cytokinins (Salopek-Sondi and others 2002). Indeed, endogenous cytokinins (Tarkowski and others 2006) and gibberellins (Ayele and others 2010) were identified in floral and fruit tissues and found to be important regulators of sepal greening. Treatment of the depistillated flowers with auxins IAA and 4-Cl-IAA did not affect the greening process, but 4-Cl-IAA stimulated peduncle elongation (Salopek-Sondi and others 2002). In this study, we examined reproductive development of $H$. niger and identified free IAA and seven amino acid conjugates. Conjugates IAA-Val, IAA-Gly, and IAA-Phe were found recently by the same authors (Pěnčík and others 2009) in H. niger for the first time in higher plants. The levels of IAA and its amino acid conjugates were quantified in intact floral and fruit tissues at different stages of development and in unfertilized and depistillated flowers. With respect to these data the role of auxin in Christmas rose development is discussed.

\section{Materials and Methods}

\section{Plant Material}

Flowers of the Christmas rose (Helleborus niger L. ssp. niger) were collected at a woodlot in the Pharmaceutical Botanical Garden "Fran Kušan" of the Faculty of Pharmacy and Biochemistry, University of Zagreb, in two different growth seasons. The material was collected to gain insight into auxin dynamics during the whole life cycle of a Christmas rose flower, comprising a series of six flower bud developmental stages (pre-anthesis), two stages of anthesis (Female and Male phase), and four stages of postanthesis development (Light green, Advanced green, Green, and Almost ripe) (Fig. 1).

Unfertilized flowers were obtained by enclosing emasculated flower buds in sacks of gauze to prevent crosspollination. In depistillated flowers, pistils and anthers were surgically removed at the bud stage as described earlier (Salopek-Sondi and others 2000).

In the flowers collected for auxin analysis, flower parts were separated (sepals, pistils or developing fruit, anthers, and peduncles). Some almost-ripe fruits were separated into seeds and pericarps. The plant material was stored at $-80^{\circ} \mathrm{C}$ until further use.

\section{Endogenous Auxins Analysis}

To assess the dynamics of auxins during flower and fruit development of the Christmas rose, endogenous auxin levels (precursor IEt, free IAA, and amide conjugates) were determined in the different tissues, in two growth seasons, by LC-MS/MS [consisting of a triple-quadrupole
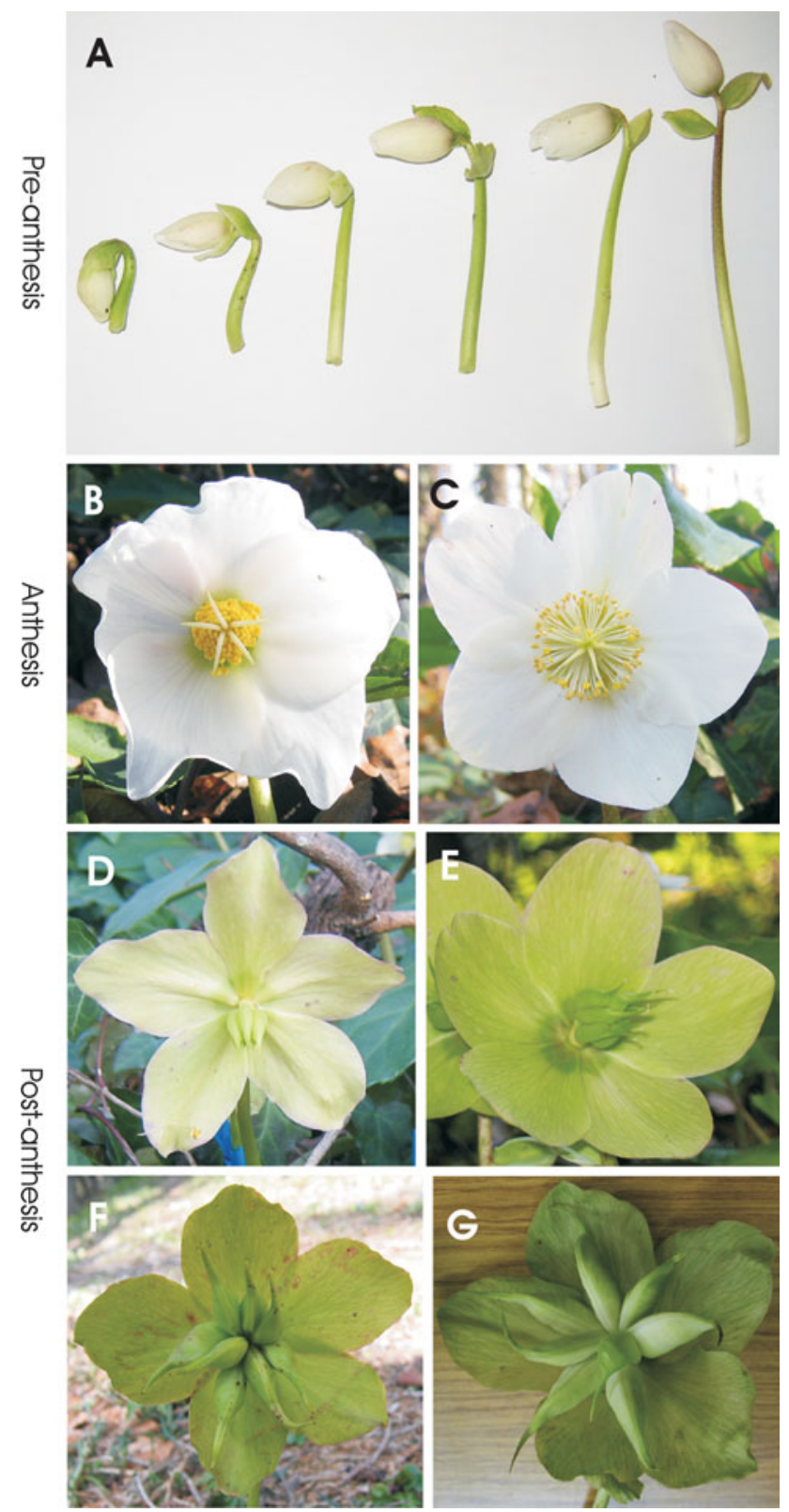

Fig. 1 Development of the Christmas rose (Helleborus niger L.) through six bud stages at pre-anthesis (a), Female (b), and Male (c) stages at anthesis, and Light green (d), Advanced green (e), Green (f), and Almost ripe (g) stages at post-anthesis

mass spectrometer (Quatro micro API tandem; Waters) and an Acquity UPLC System (Waters) equipped with a Symmetry C18 column (Waters)] using ${ }^{15} \mathrm{~N}$ - and/or ${ }^{2} \mathrm{H}_{5}$ labeled internal standards, as described previously (Pěnčík and others 2009). The analytical protocol that we used is suitable for isolation and quantification of IAA and a broad range of its amino acid conjugates and does not allow isolation (quantification) of protein conjugates of IAA. Regarding ester conjugates of IAA, the capability of the protocol to retain them has not been tested because corresponding standards were not available to us. IAA and 
related indole compounds were obtained from OlChemIm (Olomouc, Czech Republic). ${ }^{15} \mathrm{~N}-$ and/or ${ }^{2} \mathrm{H}_{5}$-labeled internal standards were prepared according to the method of Ilić and others (1997). All reagents and solvents were purchased from Sigma-Aldrich (St. Louis, MO, USA).

Briefly, the frozen plant tissue [30 mg FW (fresh weight)] was ground in liquid nitrogen and extracted with $1 \mathrm{ml}$ of cold phosphate buffer $(50 \mathrm{mM}, \mathrm{pH} 7.0)$ supplemented with $0.02 \%$ Na-diethyldithiocarbamate, and a mixture of standards $\left(\left[{ }^{2} \mathrm{H}_{5}\right]\right.$ IAA, $\left[{ }^{2} \mathrm{H}_{5}\right]$ IEt, $\left[{ }^{15} \mathrm{~N},{ }^{2} \mathrm{H}_{5}\right]$ IAA-Ala, $\left[{ }^{15} \mathrm{~N},{ }^{2} \mathrm{H}_{5}\right]$ IAA-Asp, $\left[{ }^{15} \mathrm{~N},{ }^{2} \mathrm{H}_{5}\right]$ IAA-Glu, $\left[{ }^{15} \mathrm{~N},{ }^{2} \mathrm{H}_{5}\right]$ IAA-Gly, $\left[{ }^{15} \mathrm{~N},{ }^{2} \mathrm{H}_{5}\right]$ IAA-Leu, $\left[{ }^{15} \mathrm{~N},{ }^{2} \mathrm{H}_{5}\right]$ IAA-Phe, and $\left[{ }^{15} \mathrm{~N},{ }^{2} \mathrm{H}_{5}\right]$ IAA-Val) was added to each extract. Following centrifugation $(36,000 \mathrm{~g}$, $10 \mathrm{~min}, 4^{\circ} \mathrm{C}$ ), samples were acidified with $1 \mathrm{M} \mathrm{HCl}$ to $\mathrm{pH} 2.7$ and applied on a C8 column (Bond Elut, $500 \mathrm{mg}$, Varian). After column washing with methanol (10\%) and formic acid $(1 \%)$, the analyte was eluted with methanol (70\%) acidified with formic acid (1\%), and evaporated to dryness. The extract residue was dissolved in $100 \mu \mathrm{l}$ of methanol acidified with concentrated $\mathrm{HCl}(0.1 \%)$, and methylated with $300 \mu \mathrm{l}$ of ethereal solution of diazomethane. Following $10 \mathrm{~min}$ of reaction, the mixture was evaporated under a nitrogen stream at $40^{\circ} \mathrm{C}$, the residue was dissolved in $50 \mu \mathrm{l}$ of ethanol $(70 \%)$ and $450 \mu \mathrm{l}$ of phosphate buffer $\left(20 \mathrm{mM} \mathrm{NaH}_{2} \mathrm{PO}_{4}, 15 \mathrm{mM}\right.$ $\mathrm{NaCl}, \mathrm{pH}$ 7.2), and the sample was passed through the precolumn containing immobilized BSA and was applied on an immunoaffinity column with polyspecific polyclonal antibodies against IAA (that is, antibodies interacting with all the studied indole compounds). Polyspecific polyclonal antibodies against IAA and its conjugates were obtained by immunizing rabbits with an IAA-protein conjugate as described recently by Pěnčík and others (2009). As the authors reported, the capacity and recovery of the columns, estimated by application of various amounts of indole-3acetamide, was about $3 \mathrm{nmol}$ and $95-100 \%$, respectively.

The column was then washed with water (three times $3 \mathrm{ml}$ ) and the analyte was eluted with $3 \mathrm{ml}$ of cold methanol $\left(-20^{\circ} \mathrm{C}\right)$ and evaporated to dryness. Separation was performed on an Acquity UPLC System (Waters) equipped with a Symmetry C18 column $(5 \mu \mathrm{m}, 2.1 \times 150 \mathrm{~mm}$, Waters) at $30^{\circ} \mathrm{C}$ and a flow rate of $250 \mu \mathrm{l} / \mathrm{min}$ using the following linear gradient of $10 \mathrm{mM}$ aqueous formic acid (solvent A) and methanol containing $10 \mathrm{mM}$ formic acid (solvent B): $25 \%$ solvent B for 1 min, gradient of solvent B to $38 \%$ (7 $\mathrm{min}$ ), $40 \%$ (12 $\mathrm{min}$ ), $58 \%$ (15 $\mathrm{min}$ ), and $60 \%$ (26 min). The effluent was introduced into the ion source of the Quatro micro API tandem quadrupole mass spectrometer (Waters) under the following conditions: the capillary voltage, $+500 \mathrm{~V}$; desolvation gas flow, $500 \mathrm{l} / \mathrm{h}$; desolvation temperature, $350^{\circ} \mathrm{C}$; and source block temperature, $100^{\circ} \mathrm{C}$. Instrument settings and multiple reaction monitoring (MRM) transitions of individual compounds were applied as reported earlier (Pěnčík and others 2009).
Photosynthesis Measurement

Sepal greening was monitored in vivo using a Chlorophyll Content Meter (CCM-200, Opti-Sciences, Inc., Hudson, $\mathrm{NH}$, USA) which afforded chlorophyll levels in arbitrary units based on the difference of the absorbances at $600-700 \mathrm{~nm}$ (attributed to chlorophyll $a+b$ ) and at 900-1000 nm (attributed to light scattering by cell structures and nonspecific absorbance). Measurements were done for each sepal separately in its subterminal part.

To gain information about photosynthetic efficacy of sepals, we performed chlorophyll $a$ fluorescence measurements in vivo on the growing flowers. Flowers (intact controls, unfertilized, and depistillated) were examined in April when fertilized flowers were at the Green developmental stage. Chlorophyll fluorescence was measured with a pulse-amplitude-modulated photosynthesis yield analyzer (Mini Pam, Waltz). Sepals were dark-adapted for $30 \mathrm{~min}$ before measurements. The maximum quantum yield $\left(F_{\mathrm{v}} /\right.$ $\left.F_{\mathrm{m}}\right)$ in dark-adapted samples and effective quantum yields $\left(\Delta F / F_{\mathrm{m}}{ }^{\prime}\right)$ at 50,250 , and $500 \mu \mathrm{mol}$ photons $\mathrm{m}^{-2} \mathrm{~s}^{-2}$ were determined according to Schreiber and others (1994). Measurements were done in five repetitions.

Enzyme Assays and $\mathrm{H}_{2} \mathrm{O}_{2}$ Measurement

Activities of ascorbate peroxidase (APX; EC 1.11.1.11), guaiacol peroxidase (GPOD; EC 1.11.1.7), and superoxide dismutase (SOD; EC 1.15.1.1), as well as hydrogen peroxide levels were assayed in sepal extracts at the Green stage of development. Three replicates were taken from each flower treatment. The tissue was ground into fine powder using liquid nitrogen.

The extractions for APX activity were done in ice-cold $100 \mathrm{mM}$ potassium phosphate buffer $(\mathrm{pH}$ 7.0) containing $5 \mathrm{mM}$ sodium ascorbate and $1 \mathrm{mM}$ ethylenediamine tetraacetic acid (EDTA) with the addition of polyvinylpyrrolidone (PVP). The reaction mixture contained $50 \mathrm{mM}$ potassium phosphate buffer ( $\mathrm{pH} 7.0$ ) with $0.1 \mathrm{mM}$ EDTA, $50 \mathrm{mM}$ ascorbic acid, and enzyme extract. The reaction was started with the addition of $12 \mathrm{mM} \mathrm{H}_{2} \mathrm{O}_{2}$. The APX activity was measured spectrophotometrically by observing the decrease in absorbance at $290 \mathrm{~nm}$ (Nakano and Asada 1981).

The extractions for GPOD activity were done in ice-cold $100 \mathrm{mM}$ Tris- $\mathrm{HCl}$ buffer ( $\mathrm{pH}$ 8.0). The reaction mixture consisted of $5 \mathrm{mM}$ guaiacol and $5 \mathrm{mM}$ hydrogen peroxide in $200 \mathrm{mM}$ phosphate buffer (pH 5.8). GPOD activity was measured at $470 \mathrm{~nm}$ as described by Siegel and Galtson (1967).

The extractions for SOD activity were made in ice-cold $100 \mathrm{mM}$ potassium phosphate buffer $(\mathrm{pH}$ 7.5) with the addition of PVP. SOD activity was assayed by measuring its ability to inhibit the photochemical reduction of nitroblue 
tetrazolium (NBT) as described by Giannopolitis and Ries (1977). The reaction mixture consisted of $50 \mathrm{mM}$ potassium phosphate buffer ( $\mathrm{pH} 7.5$ ), $13 \mathrm{mM}$ methionine, $75 \mu \mathrm{M}$ NBT, 0.1 mM EDTA, $2 \mu \mathrm{M}$ riboflavin, and enzyme extract. The reaction mixture, that was not exposed to light, did not develop color and served as a control. The absorbance was measured at $560 \mathrm{~nm}$. One unit of SOD activity was defined as the amount of enzyme required to cause $50 \%$ inhibition of the rate of NBT reduction at $560 \mathrm{~nm}$.

Concentrations of hydrogen peroxide $\left(\mathrm{H}_{2} \mathrm{O}_{2}\right)$ were determined according to Mukherjee and Choudhuri (1983). Sepal tissue was homogenized and extracted with ice-cold acetone. Following centrifugation, titanium sulfate and $\mathrm{NH}_{4} \mathrm{OH}$ were added into extracts. Precipitate was dissolved with $2 \mathrm{M} \mathrm{H}_{2} \mathrm{SO}_{4}$. For the determination of $\mathrm{H}_{2} \mathrm{O}_{2}$ levels, the absorbance was measured at $415 \mathrm{~nm}$ and the concentration was calculated using an extinction coefficient of $1.878 / \mathrm{nM} /$ $\mathrm{cm}$.

\section{Lignin Measurement}

Lignins and lignin-like polymers were semiquantitatively estimated in the plant material as previously described (Sancho and others 1996). Christmas rose peduncles (1 g FW) were pealed (to avoid the contribution of anthocyanidin-containing peduncle envelope to the spectrophotometric measurement of lignin content), homogenized in liquid nitrogen, and rinsed in boiling water. The insoluble material was pelleted by centrifugation and resuspended in $100 \%$ ethanol. The dry residue was dissolved in $2.5 \mathrm{ml}$ of $18 \%(\mathrm{v} / \mathrm{v}) \mathrm{HCl}$ in ethanol for $2.5 \mathrm{~h}$. After this period, $200 \mu \mathrm{l}$ of $2.5 \%$ phloroglucinol-HCl (Sigma-Aldrich) was added to the mixture and the absorbance of the final supernatant was measured after $4 \mathrm{~h}$ at $540 \mathrm{~nm}$. The results were calculated as $A_{540 \mathrm{~nm}} / \mathrm{g}$ FW and expressed per total weight of the peduncle.

\section{Histological Study of Flower Peduncle}

For histological studies of vascular tissue, small pieces of peduncles were fixed in $2 \%$ glutaraldehyde in $0.05 \mathrm{M}$ cacodylate buffer ( $\mathrm{pH} \mathrm{7.2)} \mathrm{for} 45 \mathrm{~min}$ at $4^{\circ} \mathrm{C}$, and postfixed in $1 \%$ osmium tetroxide in the same buffer for $1 \mathrm{~h}$ at $4^{\circ} \mathrm{C}$. After dehydration in a graded series of ethanol, the tissue was embedded in Spurr's resin. Semithin sections $(1 \mu \mathrm{m}$ thick) of the tissue were stained with a mixture of $2 \%$ toluidine blue and $2 \%$ borax (1:1). For lignin examination, fresh, hand-made sections of peduncles were stained with $1 \%$ phloroglucinol in $70 \%$ ethanol for 2 min, followed by treatment with the concentrated $\mathrm{HCl}$ (Yuan and others 2007). Samples were examined using an Olympus BX51 light microscope.

\section{Results and Discussion}

Flower Development: Pre-anthesis, Anthesis, and Post-anthesis

The Christmas rose has extraordinarily long-lasting flowers, with the life cycle spanning about 2-6 months, depending on the weather conditions. Thus, flower development may start at any time from late November to midApril. The seeds generally mature by May or early June (Salopek-Sondi and Magnus 2007). Because flower development is highly dependent on ambient temperature and could not be defined on an absolute time scale, we defined the developmental stages herein by morphological characteristics (Fig. 1). Six pre-anthesis bud stages were collected in February and categorized according to total peduncle length (stage I: $1-2.5 \mathrm{~cm}$, stage II: $2.5-4 \mathrm{~cm}$, stage III: $4-6 \mathrm{~cm}$, stage IV: $6-8 \mathrm{~cm}$, stage V: $8-10 \mathrm{~cm}$, and stage VI: $10-12 \mathrm{~cm})$. When the bud appeared above ground it was already $1-1.5 \mathrm{~cm}$ long (measured from the base of the bud to the tip of unopened sepals) and its length increased slightly while its peduncle elongated up to tenfold during investigated pre-anthesis stages (Fig. 1a). Bud length then increased about twice (up to $3 \mathrm{~cm}$ ) before unfolding at anthesis. Flower opening was followed by a period during which only the pistils were receptive, while the immature anthers were arranged in a ring at the base of the carpels (Female phase, Fig. 1b). Depending on ambient temperatures, the Male phase (Fig. 1c) began, usually 1-2 weeks later, with the elongation of the filaments, and ended with anther abscission. Following fertilization, the post-anthesis period of flower development began and was categorized by the degree of chlorophyll accumulation in the sepals (which persisted until fruit maturity) as Light green (the first greenish tinge, Fig. 1d), Advanced green (greening well advanced, Fig. 1e), Green (sepal greening reached stationary phase; fruit in the phase of significant growth and seed filling, Fig. 1f), and Almost ripe (seeds almost ripe; sepals at the phase when chlorophyll levels start to decline, Fig. 1g). Anthesis and post-anthesis developmental stages were described and characterized also by the weights of the sepals and the pistils or developing fruit, and by fruit lengths, as published earlier (Salopek-Sondi and others 2002; Salopek-Sondi and Magnus 2007). Fruit increased gradually, and its overall growth proceeded in concert with sepal greening. Fruit length increased about threefold, while fresh weight accumulation of the fruit increased six- to sevenfold until the Almost ripe stage. The peduncle grew significantly in the pre-anthesis and anthesis periods, after which it reached its full length (approximately $20 \mathrm{~cm}$ ) and eventually increased only slightly during the post-anthesis period. 
How Does Emasculation or Depistillation Influence Flower Development?

The fate of the attractive, white Christmas rose flowers is strongly influenced by fertilization and developing fruits (Salopek-Sondi and others 2000, 2002; Salopek-Sondi and Magnus 2007). Development of intact flowers is characterized by processes such as intensive peduncle elongation at pre-anthesis and anthesis, flower opening and sepal growth at anthesis, and sepal greening at post-anthesis during which fruit is developing. In contrast, flowers in which only anthers were removed and fertilization prevented (unfertilized) or entire reproductive organs were excised (depistillated) in the bud stage (size of bud was $2-2.5 \mathrm{~cm}$ ) did not pass through the entire developmental process. The impact of emasculation or depistillation on perianth and peduncle development was investigated and is discussed below.

\section{Impact on Perianth Greening}

The greening process of Christmas rose sepals was investigated previously at the ultrastructural and biochemical levels through several stages of development (SalopekSondi and others 2000). In our study, chlorophyll accumulation in sepals was monitored in detail through the entire post-anthesis period of flowers by use of a chlorophyll meter (Fig. 2). As can be seen in the sepals of fertilized flowers, the chlorophyll level increased to a value of approximately 3.5 at the stationary phase (Green stage, which is also the period of intensive fruit growth). As development proceeded towards the Almost ripe stage, the chlorophyll level started to decline. The greening process

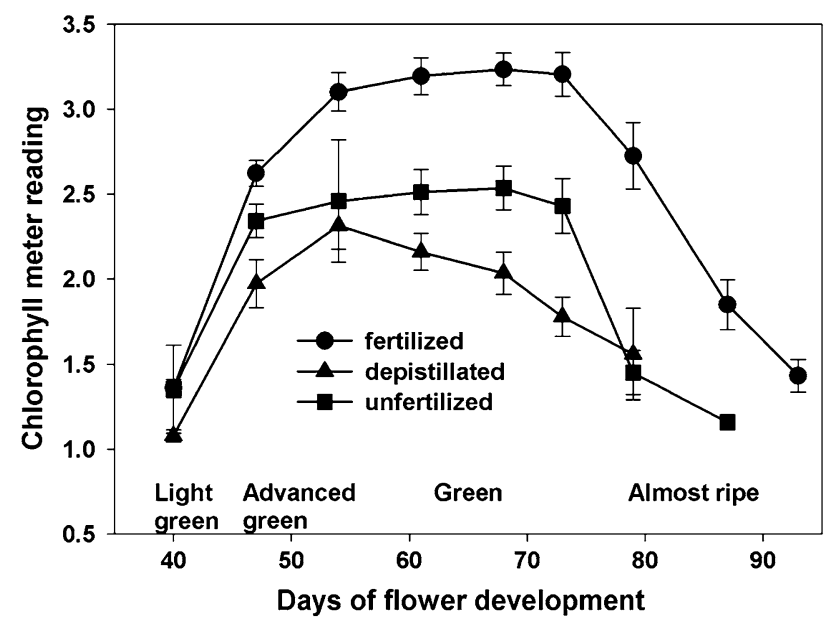

Fig. 2 Sepal greening dynamics monitored by a chlorophyll meter in fertilized control (circles), unfertilized (squares), and depistillated (triangles) flowers during post-anthesis. Data are arithmetic mean \pm SE $(n=20-25)$

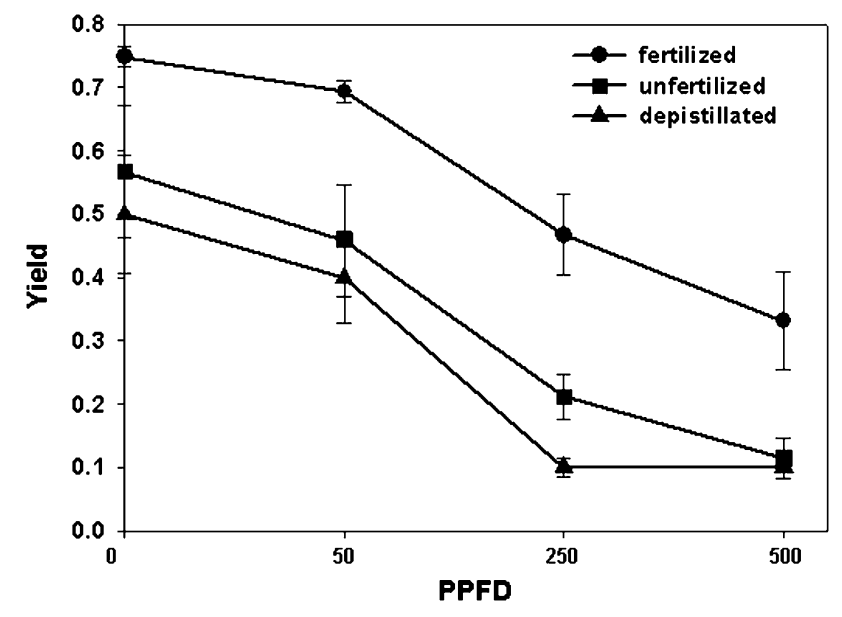

Fig. 3 Photosynthetic efficacy of sepals of fertilized (circles), unfertilized (squares), and depistillated (triangles) flowers. Measurements were done in vivo on the flowers at Green stage. The maximum quantum yield $\left(F_{\mathrm{v}} / F_{\mathrm{m}}\right)$ was determined in dark-adapted samples (at 0 PPFD), and effective quantum yields $\left(\Delta F / F_{\mathrm{m}}{ }^{\prime}\right)$ were determined at 50 , 250 , and $500 \mu \mathrm{mol}$ photons $\mathrm{m}^{-2} \mathrm{~s}^{-2}$. Data are arithmetic mean $\pm \mathrm{SE}$ $(n=5)$

of sepals was significantly inhibited upon depistillation or emasculation. Chlorophyll accumulation in the sepals of unfertilized and depistillated flowers never reached the level of fertilized ones, being more impaired by depistillation than by emasculation. Thus, the chlorophyll level in depistillated flower sepals reached about $70 \%$ of the level identified in fertilized flower sepals, after which chlorophyll rapidly declined. The chlorophyll accumulation curve of unfertilized flowers was similar to that of fertilized ones, with a significantly lower maximum. To gain data on the photosynthetic efficacy of Green stage sepals, chlorophyll fluorescence measurement in vivo was performed. An effective quantum yield $\left(\Delta F / F^{\prime}{ }_{\mathrm{m}}\right)$ of photosystem II (PSII) was calculated for Green stage sepals of fertilized and their unfertilized and depistillated neighbors (Fig. 3). The maximum quantum yield (measured in dark adopted plants, $\left.F_{\mathrm{v}} / F_{\mathrm{m}}\right)$ of unfertilized and depistillated flowers was 76 and $67 \%$, respectively, of the value measured for a fertilized control. Effective quantum yields of PSII $\left(\Delta F / F^{\prime}{ }_{m}\right)$ were decreased significantly in treated flowers, reaching only $20-30 \%$ of the value measured in fertilized flowers. Because $\Delta F / F^{\prime}{ }_{m}$ corresponds to the proportion of the light absorbed by chlorophyll associated with PSII (Maxwell and Johnson 2000), the decrease in $\Delta F / F^{\prime}{ }_{\mathrm{m}}$ (Fig. 3) was in accordance with the values of chlorophyll meter readings in the sepals of the examined Christmas rose flowers (Fig. 2).

Based on the visual observation of flowers through development and on biochemical measurements, including chlorophyll accumulation (Fig. 2) and PSII efficiency 

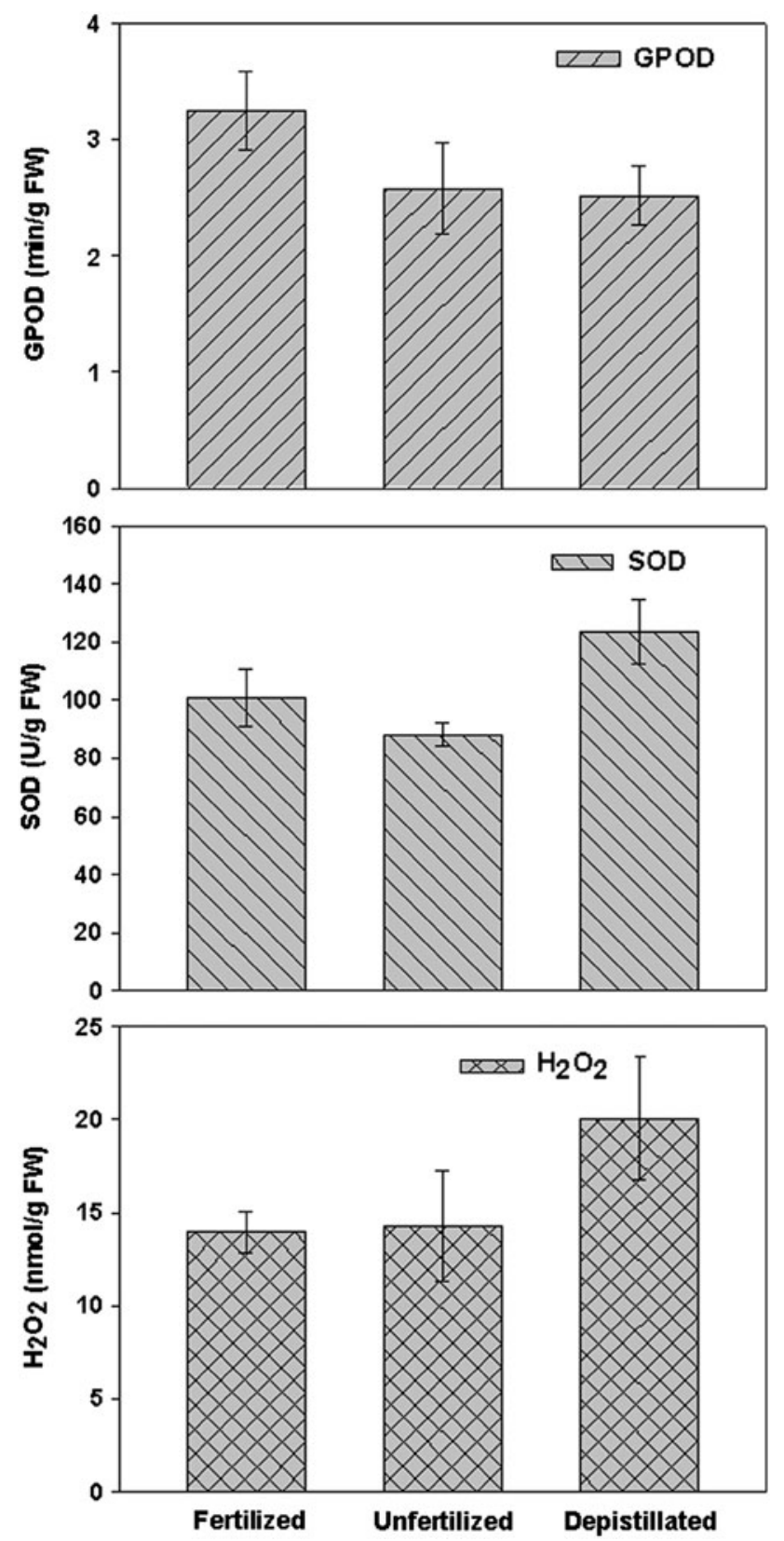

Fig. $4 \mathrm{H}_{2} \mathrm{O}_{2}$ and enzyme assays: guaiacol peroxidase (GPOD) and superoxide dismutase (SOD) detected in the sepals of fertilized, unfertilized, and depistillated flowers at the Green stage of postanthesis. Data are arithmetic mean $\pm \operatorname{SE}(n=3)$

(Fig. 3), it may be that the unfertilized and, especially, depistillated flowers, also entered the process of senescence earlier than fertilized ones. Data on the $\mathrm{H}_{2} \mathrm{O}_{2}$ level and activities of antioxidant enzymes, particularly in the sepals of depistillated flowers, are in agreement with this statement (Fig. 4). The activity of GPOD peroxidase (Fig. 4a) was decreased in the unfertilized and depistillated flowers, whereas that of APX was mostly unchanged (data not shown). The level of $\mathrm{H}_{2} \mathrm{O}_{2}$ was elevated significantly in depistillated flowers compared with that in control and unfertilized flowers (Fig. 4c). The activity of SOD (Fig. 4b), which dismutases $\mathrm{O}_{2}{ }^{-}$to $\mathrm{H}_{2} \mathrm{O}_{2}$, correlated with the level of $\mathrm{H}_{2} \mathrm{O}_{2}$ found in the investigated sepals. The levels of lipid peroxidation and protein carbonyls that were also measured did not show significant changes (data not shown). An increased level of endogenous $\mathrm{H}_{2} \mathrm{O}_{2}$ is reported to be connected with senescence of the leaf (Niewiadomska and others 2009) and flower tissue (Panavas and Rubinstein 1998; Kumar and others 2008). The decrease of protective enzyme activity is usually in accordance with the increase in $\mathrm{H}_{2} \mathrm{O}_{2}$ levels during plant tissue senescence. In our study, depistillation treatment seems to cause a stronger tissue oxidation state and leads the flower into the process of earlier senescence in comparison to fertilized and unfertilized counterparts.

\section{Impact on Peduncle Elongation and Vascular Anatomy}

The growth of the peduncle was monitored in intact flowers and their emasculated and depistillated counterparts through pre-anthesis, anthesis, and post-anthesis development. The most prominent elongation of the peduncle was observed in the pre-anthesis period (Fig. 1a) when its length increased up to tenfold (from 1 to $10 \mathrm{~cm}$ ). Thereafter, the peduncle additionally elongated about twice during the anthesis and early post-anthesis periods, reaching approximately $18-20 \mathrm{~cm}$ at the stationary phase (Fig. 5). In the unfertilized and depistillated flowers, peduncle growth was stunted throughout their life span and never reached the length of those of fruit-bearing flowers. Thus, the peduncles

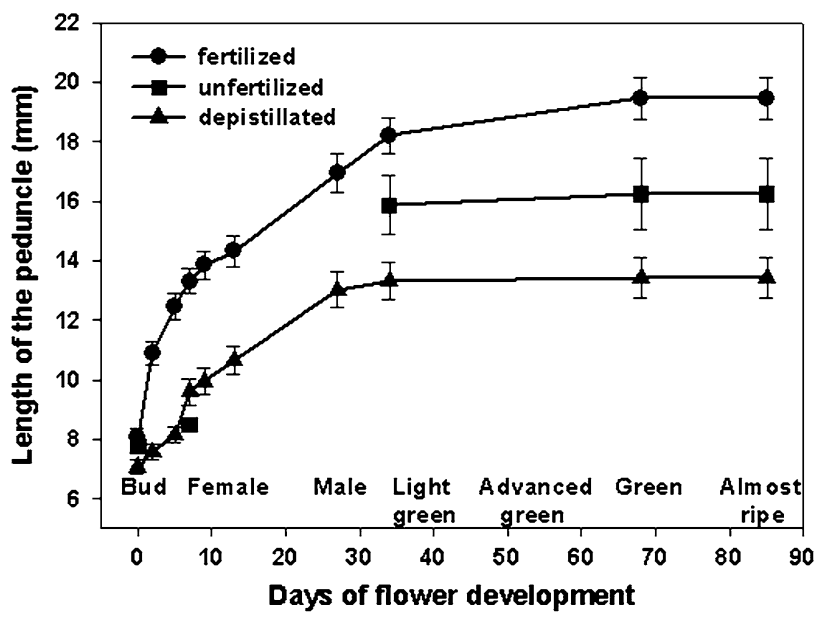

Fig. 5 Peduncle elongation dynamics of fertilized controls (circles), unfertilized (squares), and depistillated (triangles) flowers. Measurement started at the pre-anthesis when the length of peduncle was $7.6 \pm 0.267 \mathrm{~cm}$, and the surgical treatments (emasculation and depistillation) were done in two selected groups, which were therefore monitored as unfertilized and depistillated flowers, respectively. Data are arithmetic mean $\pm \operatorname{SE}(n=20-25)$ 
of unfertilized and depistillated flowers at the stationary phase reached 83 and $68 \%$ of the length of fertilized flower peduncle, respectively (Fig. 5). A similar effect of flower stalk growth inhibition upon bud decapitation or emasculation was observed in the miniature Cymbidium orchid (Ohno and Kako 1991), the tulip (Hanks and Rees 1977; Saniewski and De Munk 1981), and the daffodil (Edelbluth and Kaldewey 1976; Hanks and Rees 1977).

In addition to monitoring the dynamics of peduncle elongation, we also examined the peduncle cross-section anatomy of fruit-bearing versus depistillated flowers, with particular attention placed on the vascular apparatus. The vascular bundles of Helleborus peduncles appeared widely spaced, collateral, and typically with the V-shaped xylem concave on the side toward the phloem (representative shown in Fig. 6f), as usually reported for the herbaceous plants of the Ranunculaceae family (Metcalfe and Chalk 1972). Looking through the development of the peduncle, semithin sections of vascular tissue showed phloem and xylem being gradually fully developed until the last stage (Fig. 6b, d, f). As flower development proceeded, an interfascicular cambium layer was clearly distinguished between phloem and xylem. For more detailed analyses, lignin detection, in a qualitative manner, was employed at the anatomical level by using the phloroglucinol-HCl (Wiesner) reaction (Yuan and others 2007), whereas semiquantitative estimation of lignin was done spectrophotometrically (Sancho and others 1996). The major change in the vascular bundle during peduncle growth and development was in lignin deposition in the sclerenchyma (Fig. 6a, c, e). Furthermore, the sclerenchyma was not even noticeable at the bud stage of development (Fig. 6a). As perianth greening occurred and the peduncle elongated, lignin deposition began, thus forming a sclerenchyma noticeable as a light red color mostly adjacent to the tip points of vascular tissue (Fig. 6c). As flower development proceeded toward the final Almost ripe stage, a very red sclerenchyma was observed surrounding the vascular bundle (Fig. 6e). In contrast, lignin deposition in the depistillated flower peduncle was arrested somewhere at the stage between Light green and Green: only a faint phloroglucinol-HCl staining is evident close to vascular tissue (Fig. 6g). Furthermore, vascular bundles found in the peduncle of the depistillated flowers were generally smaller in comparison to that found in the peduncle of fruitbearing flowers. Semiquantitative estimation of total lignins during peduncle development correlated with anatomical examination (Fig. 7). The amount of lignin and lignin-like polymers increased gradually in the peduncle from bud stage III (in which peduncle length was 4-6 cm and peduncle FW was $0.69 \mathrm{~g}$ ) until the Almost ripe stage of intact flowers (in which peduncle length was approximately $20 \mathrm{~cm}$ and peduncle FW was $3.56 \mathrm{~g}$ ). Depistillated peduncles at the Almost ripe stage (peduncle length was approximately $13 \mathrm{~cm}$ and peduncle FW was $1.03 \mathrm{~g}$ ) accumulated significantly lower amounts of total lignin, only $19 \%$ of the value measured in intact controls.

The post-anthesis period of the intact flower is marked by fruit development. It is the period of intensive assimilate
Fig. 6 Vascular cross-section anatomy of peduncles in the intact control: bud stage III (a, b), Light green $(\mathbf{c}, \mathbf{d})$, and Almost ripe (e, f), as well as depistillated flower at the last stage of development (Almost ripe) (g, h). Panels a, c, e, and g present lignin detection (red/ dark) obtained with phloroglucinol on the fresh, hand-made, peduncle cross sections. Panels b, d, f, and $\mathbf{h}$ present semithin sections ( $1 \mu \mathrm{m}$ thick) of flower peduncle stained with a mixture of $2 \%$ toluidine blue and $2 \%$ borax (1:1). $X$ xylem; $S c$ sclerenchyma; $P h$ phloem; Ic interfascicular cambium. Scale bar $=100 \mu \mathrm{m}$ (Color figure online)
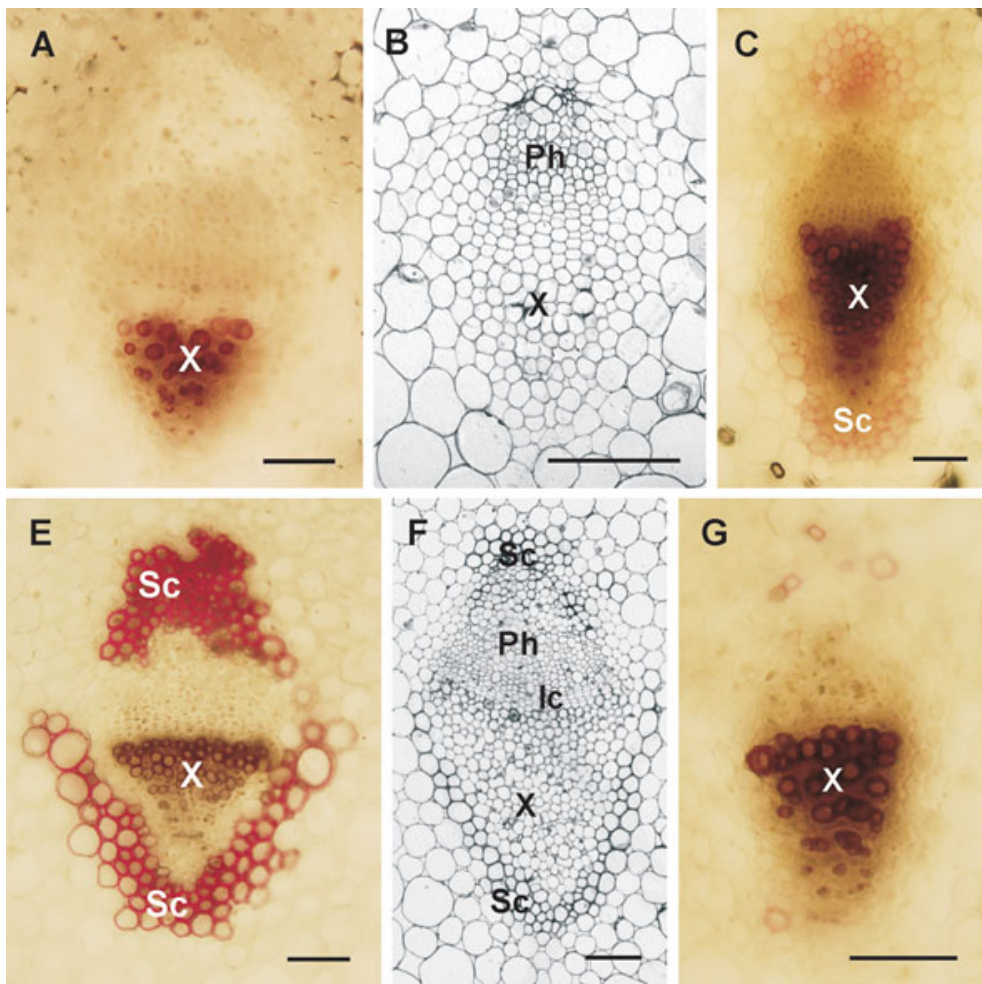
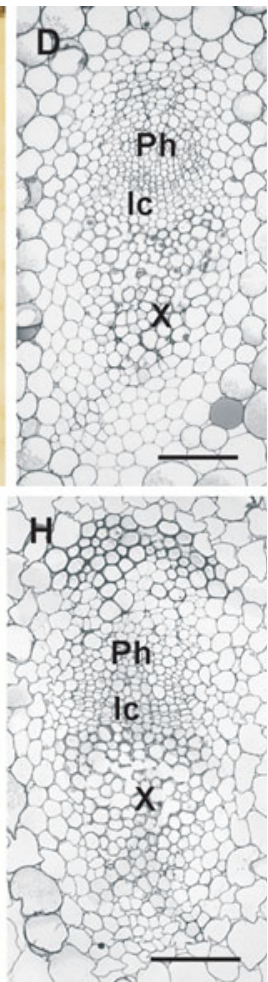


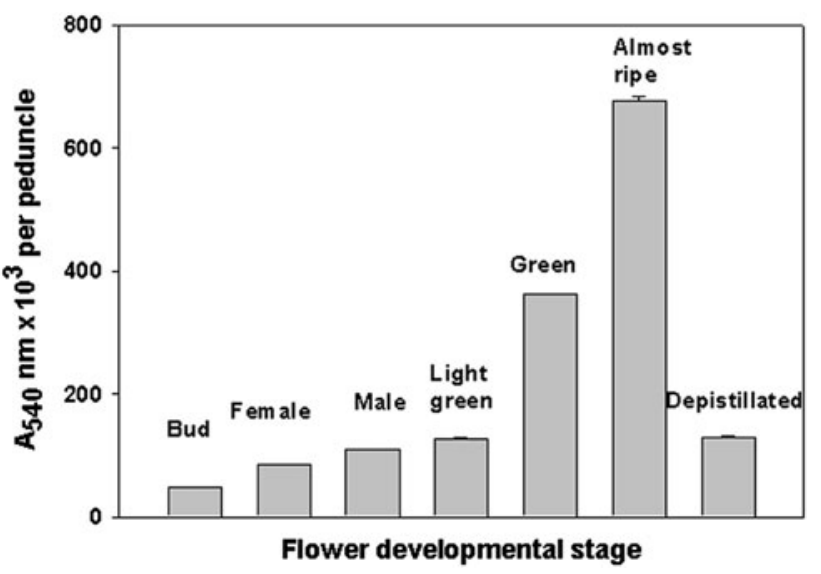

Fig. 7 Semiquantitative estimation of lignins and lignin-like polymers in the peduncle of intact control through development from bud stage III to Almost ripe, as well as in depistillated flower at the last stage of development (Almost ripe). Data are arithmetic mean $\pm \mathrm{SE}$ $(n=3)$

production in photosynthetically active sepals and leaves and their transport from "source" to "sink" plant organs. Due to transport of assimilates and water, there is a strong demand for a well-developed vascular tissue in the peduncle.

\section{Endogenous Auxin Profile of Intact Flowers During Development}

The auxin profile during development of the Christmas rose flower, involving pre-anthesis, anthesis, and postanthesis, was determined in the different tissues by
LC-MS/MS as described earlier (Pěnčík and others 2009). Free IAA and amide conjugates, as well as a precursor of IAA biosynthesis, IEt, were identified and quantified.

\section{Indole-3-ethanol (IEt)}

IEt or tryptophol has been found as an endogenous metabolite in many plants as part of IAA metabolism (Laćan and others 1985). It appears to be a reversible sidebranch product in the biosynthesis of indole-3-acetaldehyde, the precursor of IAA (Ljung and others 2002; Quittenden and others 2009). In this study, we identified IEt mostly in the immature anthers and sporadically in developing pistils during pre-anthesis development (in the range of 1-3.5 pmol/g FW) (Fig. 8a), and later in immature seeds (at the level of $28.0 \pm 15.3 \mathrm{pmol} / \mathrm{g} \mathrm{FW}$, Table 1). The occurrence of IEt seems to be organ-specific and does not necessarily follow the level of IAA.

\section{Free IAA Profile}

In the pre-anthesis developmental period auxins were measured in tissues through six bud stages characterized by intensive peduncle elongation (Fig. 8b). Pistils (gynoecium), followed by anthers, were the major source of free IAA. There was a slight tendency for the level of free IAA to decrease toward advanced bud stages. The perianth and peduncle contained a lower level of free IAA in comparison to reproductive organs, with minor fluctuations (approximately 10 and $15 \mathrm{pmol} / \mathrm{g} \mathrm{FW,} \mathrm{respectively).}$
Fig. 8 Endogenous IAA analyzed in different floral tissues and fruits in intact control flowers during preanthesis (b), anthesis (c), and post-anthesis (d). IEt has been identified and quantified only at pre-anthesis stages (a). Data are arithmetic mean $\pm \mathrm{SE}(n=2)$
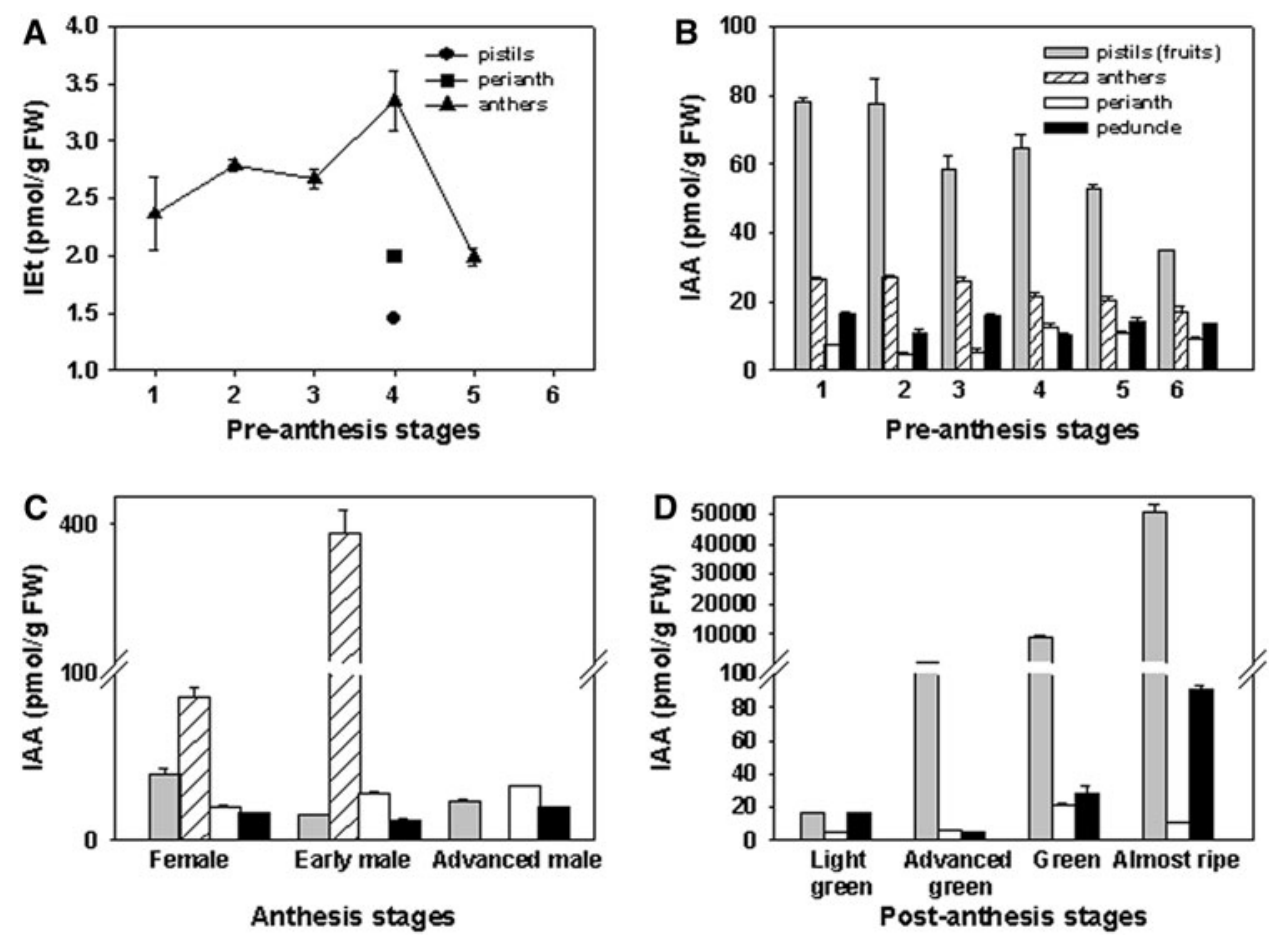
However, the peduncle was intensively elongated at the observed period (Fig. 1a); peduncle weight was increased gradually (from $0.3 \mathrm{~g}$ at the first bud stage to approximately $1.5 \mathrm{~g}$ at the last bud stage). Thus, the sum of quantified auxins per peduncle increased approximately five times during the pre-anthesis period.

At anthesis, anthers, until their abscission at the advanced male stage, accumulated free IAA up to $400 \mathrm{pmol} / \mathrm{g} \mathrm{FW}$ (Fig. 8c). Anthers were also reported as a rich source of auxins in Arabidopsis during flower development (Cecchetti and others 2008). It is suggested that auxin synthesized in the anthers contributes to the regulation of filament elongation and plays a major role in coordinating anther dehiscence and pollen maturation. In addition to regulating processes inside male reproductive tissues, it is also suggested that auxins originating in anthers may be basipetally transported and may stimulate peduncle elongation in Cymbidium orchids (Ohno and Kako 1991).

Post-anthesis was characterized by fruit growth and development as well as sepal greening. At the post-anthesis stages, developing fruit became a tremendous source of auxin, reaching over 50,000 pmol free IAA/g FW at the last stage (Fig. 8d). Looking into auxin abundance inside the Almost ripe fruits, approximately $98 \%$ of IAA was present in the seeds and only $2 \%$ in pericarps (Table 1 ). In accordance with auxin increase in developing fruit, significant accumulation of free IAA was noticed in the peduncle, reaching almost $100 \mathrm{pmol} / \mathrm{g} \mathrm{FW}$ at the last stage (Fig. 8d).

\section{Amide Conjugates of IAA}

The profile and dynamics of amino acid conjugates of IAA during reproductive development are shown in Fig. 9. IAA conjugates with Asp and Glu were the most abundant amide conjugates in the flower tissues during development, generally, following the distribution of free IAA. During pre-anthesis, IAA-Asp and IAA-Glu were found mostly in the anthers, with peaks at the advanced stages (Fig. 9a). Pistils at the first two developmental stages contained about half of the total conjugates found in the anthers, with a significant decrease toward the advanced stages. Perianth and peduncle generally contained lower levels of total amide conjugates in comparison to reproductive organs. Results showed that abundance of IAA-Asp and IAA-Glu varied in the various flower parts. Thus, anthers contained predominantly IAA-Glu over IAA-Asp; pistils and perianth showed the opposite situation (more IAA-Asp in comparison to IAA-Glu), whereas the peduncle contained only a low level of IAA-Glu. It was also reported earlier that distribution of IAA-Asp and IAA-Glu follows the distribution of free IAA during vegetative development of 
Fig. 9 Endogenous amide conjugates of IAA in different floral tissue of fertilized flowers during reproductive development. IAA-Asp and IAA-Glu, the most abundant conjugates, are shown at preanthesis (a), anthesis (b), and post-anthesis (c), whereas other amide conjugates are detected at post-anthesis (d). Data are arithmetic mean $(n=2)$. SEs were in the same range as for the data shown on Fig. 8
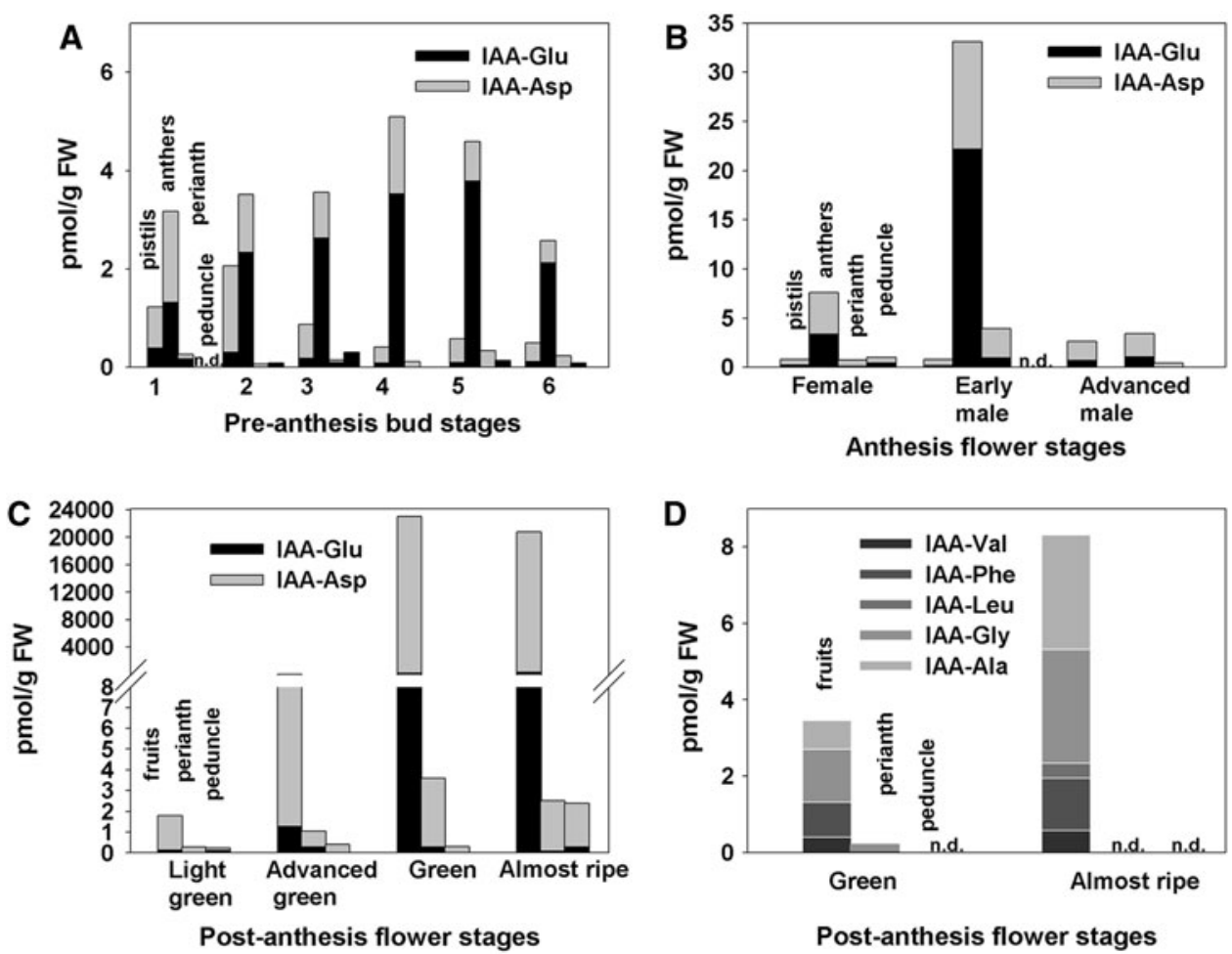

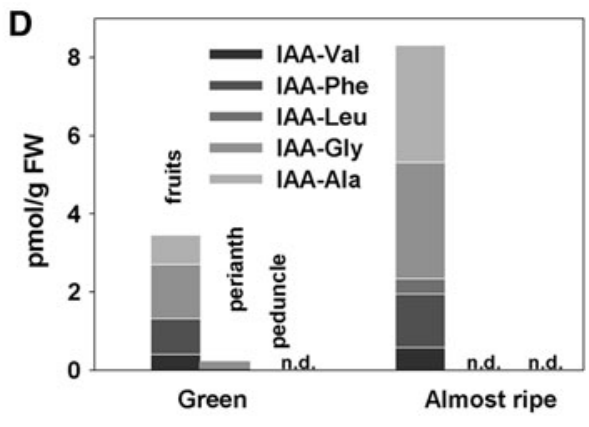

Post-anthesis flower stages
Arabidopsis, although their abundance may vary at the spatial and temporal base (Kowalczyk and Sandberg 2001).

At anthesis, IAA-Glu and IAA-Asp were found in anthers predominantly in the Female and early Male stages until their abscission, which corresponded well with the IAA level. The conjugates accumulated slightly in the pistils and perianth, whereas in the peduncle they retained very low or undetectable levels (Fig. 9b). In addition to IAA-Glu and IAA-Asp, some novel amide conjugates such as IAA-Ala and IAA-Val were identified in anthers of the early Male stage in the amount of 1.489 and $0.217 \mathrm{pmol} / \mathrm{g}$ $\mathrm{FW}$, respectively.

At the post-anthesis stages, developing fruit became a tremendous source of conjugated auxins, reaching up to 20,800 pmol of amide conjugates per $\mathrm{g} \mathrm{FW}$ at the last stage (Fig. 9c, d). The most abundant conjugate in Almost ripe fruit was IAA-Asp (98\% of total conjugates) at the level of $20,500 \mathrm{pmol} / \mathrm{g} \mathrm{FW}$, followed by IAA-Glu (about $309 \mathrm{pmol} / \mathrm{g} \mathrm{FW}$ ). In addition to conjugates with Glu and Asp, amide conjugates with Val, Phe, Leu, Gly, and Ala were identified in fruits at the last two developmental stages (Fig. 9d). Alongside IAA amino acid conjugates described earlier in different plant species (reviewed by Bajguz and Piotrowska 2009), novel conjugates with Val, Gly, and Phe were identified (Pěnčík and others 2009) and quantified in the Christmas rose fruits for the first time in vascular plants. Amide conjugates with Val, Phe, Leu, Gly, and Ala were accumulated at a lower rate, mostly in the seeds (from 0.4 to $3 \mathrm{pmol} / \mathrm{g} \mathrm{FW}$ ), and some of them in the pericarps (Table 1). IAA-Asp was the first detected amide conjugate of IAA in pea seedlings (Andreae and Good 1955) and was the predominant form in most dicotyledonous plants (see for review Ludwig-Müller 2011). It has been postulated that IAA conjugated to Asp (and possibly Glu) is an irreversible catabolite. So far, IAA-Ala has been detected in spruce (Östin and others 1992), and IAA-Ala and IAA-Leu together with IAA-Asp and IAA-Glu have been found in Arabidopsis (Tam and others 2000; Kowalczyk and Sandberg 2001). It has been suggested that other amide conjugates (with Ala, Leu, Gly, Phe, Val), which are good substrates for auxin amidohydrolases in vitro (reviewed by Ludwig-Müller 2011), participate in storage and hormone homeostasis as a slow-releasing source of free IAA (Hangarter and Good 1981). Seeds of many species are reported as rich in amide conjugates (Cohen and Bandurski 1982; Bialek and Cohen 1989; Ljung and others 2002), which are the main source of active auxins in the period of germination until young seedlings are capable of setting up their own de novo auxin biosynthesis (Rampey and others 2004).

In accordance with the increase in auxin in developing fruit, significant accumulation of free IAA was noticed in the flower peduncle as post-anthesis development proceeded (Fig. 8d), although we did not detect a significant 
level of conjugates (about $90 \mathrm{pmol} / \mathrm{g} \mathrm{FW}$ of free IAA, and just about $2.4 \mathrm{pmol} / \mathrm{g} \mathrm{FW}$ of total amide conjugates). It is interesting that the peduncle contained almost 40 times more free IAA than amide conjugates, whereas that ratio was significantly lower in the perianth (4.3) and the fruit (2.4). It is an intriguing question: What is the purpose of such a high level of free IAA in the peduncle during postanthesis development? Post-anthesis is a period of intensive production of assimilates and fruit filling, considering water and assimilate transport through the peduncle. Results of vascular cross-section anatomy during flower development (Figs. 6, 7) in accordance with the data of auxin analyses indicate that IAA may be involved in the development and maintenance of the peduncle vascular system, necessary for successful transport of water and assimilates, particularly at post-anthesis. Because other factors such as cytokinins and gibberellins are known to be involved in peduncle vascularization (Aloni and others 1990; Wolbang and others 2004; Dettmer and others 2009), additional experiments that will shed light on the auxin role in these processes will be performed in the future.
Endogenous Auxin Profile in Unfertilized and Depistillated Flowers

The fate of the Christmas rose flowers, with special attention paid to the perianth and the flower peduncle, upon emasculation or depistillation has been described earlier (Salopek-Sondi and Magnus 2007) and investigated in more detail in our study. To investigate the impact of removal of floral parts (anthers or complete reproductive organs) on the auxin profile, we measured endogenous auxins in unfertilized and/or depistillated flowers and compared them with intact controls of the same age. Firstly, we compared auxins in flowers at the 5th, 7th, and 10th day after depistillation with corresponding controls. At those time points, control flowers were at the Female to Male stages of development with a corresponding peduncle elongation of approximately $3.5 \mathrm{~cm}$ (from 11.3 to $14.8 \mathrm{~cm}$ ) and a double increase of peduncle FW (from 1.48 to $3.72 \mathrm{~g})$. At the same time, peduncles of depistillated flowers were slightly elongated (from 7.9 to $8.2 \mathrm{~cm}$ with FW increase from 1.40 to $1.54 \mathrm{~g}$ ). As can be seen in Fig. 10, free IAA was significantly accumulated in the
Fig. 10 Free IAA and amide conjugates measured in tissues of fertilized and depistillated flowers at the 5th (a, b), 7th (c, d) and 10th (e, f) day upon depistillation. Data are arithmetic mean $\pm \mathrm{SE}(n=2)$. SEs on the right panels were in the same range as for the data shown on the left panels
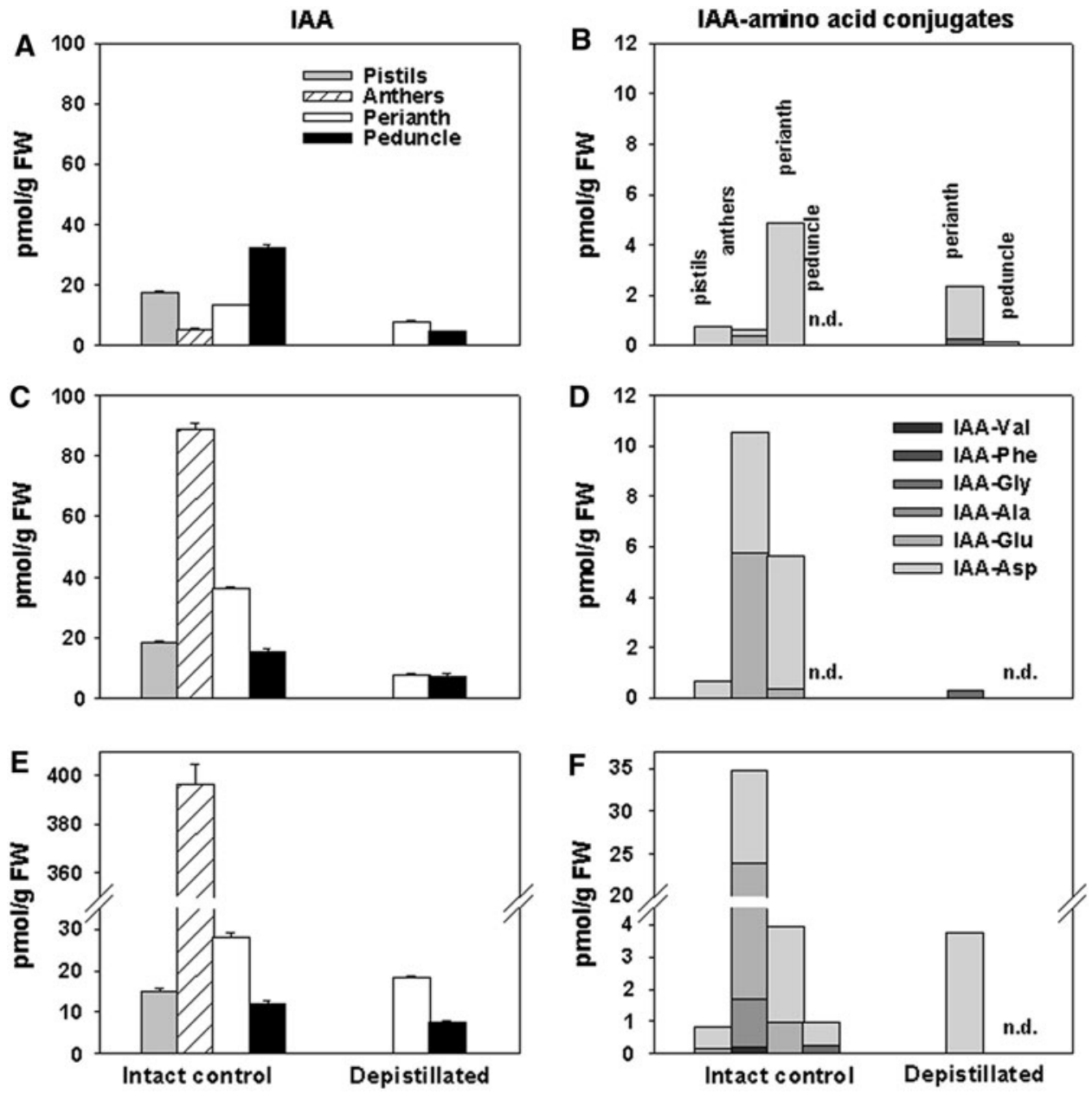

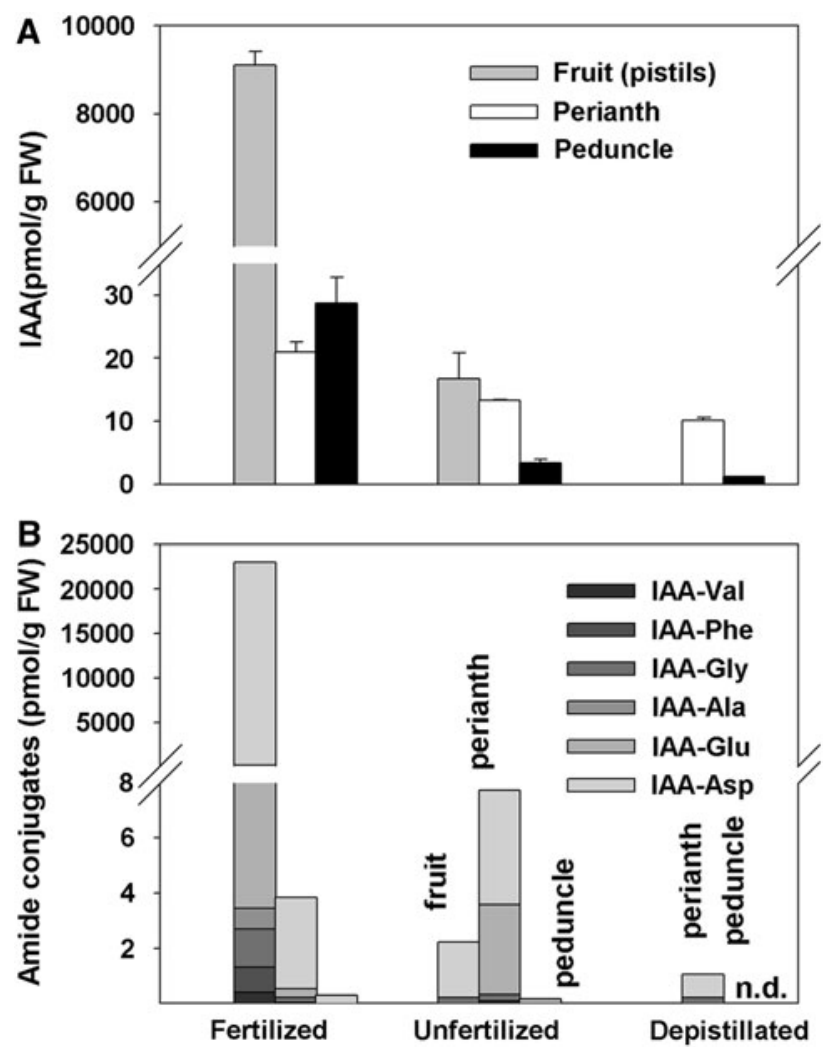

Fig. 11 Comparison of free IAA (a) and amide conjugates (b) in floral tissues of fertilized, unfertilized, and depistillated flowers at the Green developmental stage. Data are arithmetic mean $\pm \operatorname{SE}(n=2)$. SEs on the panel $\mathbf{b}$ were in the same range as for data shown on the panel a

anthers and the pistils in fertilized controls. IAA was also increased in the perianth, although it was decreased in the peduncle. However, because the peduncle was intensively growing at the observed period, total free IAA per peduncle was about 45 pmol during that period, without noticeable fluctuations. The amount of free IAA in the perianth and peduncle of depistillated flowers reached about $50 \%$ of that identified in the control. Accumulation of total IAA amide conjugates followed IAA dynamics in examined flower parts. Thus, anthers accumulated mostly IAA-Glu, then IAA-Asp, and low amounts of IAA-Ala and IAA-Val at the 10th day of investigation. Other flower parts such as pistils and perianth accumulated mostly IAA-Asp at earlier stages, with an increase in IAA-Glu toward advanced stages. The perianth of the depistillated flower accumulated lower amounts of total conjugates than controls, which is in accordance with the amount of free IAA. Not only the amount but the pattern of amide conjugates appeared to be different in depistillated flowers (mostly IAA-Asp has accumulated in depistillated perianth).

Finally, a comparison of the auxin profile in unfertilized, depistillated, and intact control flowers was done at the Green' stage of development (Fig. 11). Analyzed auxin (free and amino acid conjugates) was significantly lower in most of the examined tissues of unfertilized and depistillated flowers, respectively, in comparison to the fertilized ones. The exception was the perianth of unfertilized flowers, which contained higher levels of conjugates than that of fertilized controls. Unfertilized pistils contained only $0.06 \%$ of the total auxin detected in the developing fruit of the Green flower. The peduncle of unfertilized and depistillated flowers contained only 12 and $4 \%$ of total auxin, respectively, whereas the perianth contained 84.7 and $45.2 \%$ of that found in the fruit-bearing ones. These results imply that the perianth is capable of synthesizing more than $50 \%$ of its own auxin, independent of the presence of developing fruits. In contrast, the auxin pool in the peduncle is mostly dependent on the existence of developing fruit. It may be hypothesized that more than $90 \%$ of auxin in the peduncle is transported from the developing fruit. This may be supported by the results of Nishio and others (2010) who suggested that auxin is transported from young seeds during tomato fruit development by SIPIN1 and SIPIN2 and is accumulated in the peduncles. However, this suggestion needs to be confirmed in the Helleborus model by future experiments.

\section{Conclusion}

Among different plant hormones involved in the regulation of reproductive plant development, auxins trigger the flower and the fruit developmental programs (Cheng and Zhao 2007; Alabadi and others 2009) and participate in the coordination of processes within and between floral organs (Sundberg and Østergaard 2009). We investigated the auxin profile and dynamics as well as their possible coordinating role in the reproductive development of the Christmas rose (Helleborus niger L.) through pre-anthesis, anthesis, and post-anthesis. In addition to free IAA, IEt and seven amino acid conjugates of IAA were identified and quantified. IEt was accumulated in immature anthers and sporadically in pistils during pre-anthesis and in developing seeds during post-anthesis. It probably serves as a pool for indole-3-acetaldehyde, the immediate precursor for IAA synthesis in the period of intensive development of reproductive organs and seeds. In addition to amide conjugates described earlier in many plant species (IAA-Asp, IAA-Glu, IAA-Ala, IAA-Leu) (Bajguz and Piotrowska 2009), some novel conjugates of IAA with Val, Gly, and Phe were identified and quantified in anthers and developing seeds according to the recently established method (Pěnčík and others 2009). Although the existence of IAAVal, and IAA-Phe as endogenous plant conjugates has been strongly suggested by Kai and others (2007) based on the identification of their oxidative metabolites in Arabidopsis, 
they are confirmed in the Christmas rose. Recently, IAAVal has been found in moss (Physcomitrella patens) grown on medium supplemented with IAA (Ludwig-Müller and others 2009).

Results of our research showed that reproductive organs, pistils and anthers before fertilization, and then developing fruit at post-anthesis are rich sources of auxin. Based on the data obtained in unfertilized and depistillated flowers, one may conclude that the peduncle is dependent on mostly auxin supplied from other flower parts. Upon emasculation or depistillation at the early bud stage, the auxin content of the peduncle decreased to $50 \%$ at anthesis and then to $4 \%$ at post-anthesis development in comparison to intact controls. During pre-anthesis and anthesis, when the peduncle is significantly elongated, auxin necessary for peduncle elongation seems to be supplied mostly by the anthers at pre-anthesis and anthesis, until their abscission. It is in agreement with results obtained on Cymbidium flowers (Ohno and Kako 1991), which suggested that the peduncle is supplied mostly by auxins from the developing flower buds, especially from the anthers. Furthermore, selective removal of the floral parts in tulip and narcissus showed that gynoecium controls stem extension (Hanks and Rees 1977).

In the post-anthesis period developing fruits, mostly seeds, become tremendously rich in free and amide-conjugated IAA, causing the increase of free IAA in the peduncle. This is supported by the results of the expression analysis of the auxin efflux carriers in tomato during reproductive development (Nishio and others 2010). The authors suggested that auxin is likely transported from young seeds by SIPIN1 and SIPIN2 and accumulated in the peduncles. One of the possible roles of auxin transported from young seeds to peduncles during tomato fruit development is the prevention of abscission of fertilized flowers and young developing fruits. In Helleborus plants, unfertilized or depistillated flowers remain attached to the mother plant although sepal greening and peduncle elongation were impaired. Investigation of the vascular crosssection anatomy of the peduncle showed a noticeable deposition of lignin in the sclerenchyma surrounding vascular bundles in the peduncle of fertilized controls, whereas this process was arrested in the "auxin-poor" peduncle of depistillated flowers. It was shown earlier that the lignification level was markedly reduced in a uro "soft stem" Arabidopsis mutant in which auxin content and signaling were found to be abnormal (Guo and others 2004; Yuan and others 2007). Although auxin is the primary signaling compound necessary for regulation of lignification and overall vascular tissue development, tight crosstalk with other plant hormones such as cytokinins and gibberellins is required (Aloni and others 1990; Aloni 2004; Dettmer and others 2009). Our previous research demonstrated that cytokinins (Salopek-Sondi and others 2002; Tarkowski and others 2006) and gibberellins (Ayele and others 2010), in addition to the herein investigated auxin, are highly involved in flower and fruit development of the Christmas rose. Although cytokinins are mostly responsible for promoting sepal greening, gibberellins are shown to be involved in the greening process, but, also in coordination with auxin, in the regulation of peduncle elongation. Therefore, tight crosstalk between these and probably other plant hormones coordinates flower and fruit development of this ornamental plant. Details of the mechanism of the hormonal crosstalk during the reproductive development of the Christmas rose, with the particular role in peduncle elongation and vascular development, need to be elucidated in the future work.

Acknowledgment This manuscript is dedicated to Dr. Sc. Volker Magnus, who was involved in the research of Christmas rose development for many years. This work was supported by research grants no. 098-0982913-2829, 098-0982913-2838, 073-0731674-0841, and 073-0731674-1673 (Croatian Ministry of Science, Education and Sports), by grant MSM6198959216 (Ministry of Education, Youth and Sports of the Czech Republic) and by grant KAN200380801 (Academy of Sciences of the Czech Republic). We thank the staff of Pharmaceutical Botanical Garden "Fran Kušan" who made their Christmas rose collections available for our experiments, Dr. Sc. Kroata Hazler-Pilepić for constructive discussions connected to vascular development, and Dr. Sc. Marija Mary Sopta for critical reading of manuscript.

\section{References}

Alabadí D, Blázquez MA, Carbonell J, Ferrándiz C, Pérez-Amador MA (2009) Instructive roles for hormones in plant development. Int J Dev Biol 53:1597-1608

Aloni R (2004) The induction of vascular tissues by auxin. In: Davies PJ (ed) Plant hormones. Biosynthesis, signal transduction, action. Kluwer Academic Publishers, Dordrecht, pp 471-492

Aloni R, Tollier MT, Monties B (1990) The role of auxin and gibberellin in controlling lignin formation in primary phloem fibers and in xylem of Coleus blumei stem. Plant Physiol 94:1743-1747

Aloni R, Aloni E, Langhans M, Ullrich CI (2006) Role of auxin in regulating Arabidopsis flower development. Planta 223:315-328

Andreae WA, Good NE (1955) The formation of indoleacetylaspartic acid in pea seedlings. Plant Physiol 30:380-382

Ayele BT, Magnus V, Mihaljević S, Prebeg T, Čož-Rakovac R, Ozga JA, Reinecke DM, Mander LN, Kamiya Y, Yamaguchi S, Salopek-Sondi B (2010) Endogenous gibberellin profile during Christmas rose (Helleborus niger L.) flower and fruit development. J Plant Growth Regul 29:194-209

Bajguz A, Piotrowska A (2009) Conjugates of auxin and cytokinin. Phytochemistry 70:957-969

Bialek K, Cohen JD (1989) Free and conjugated indole-3-acetic acid in developing bean seeds. Plant Physiol 91:775-779

Burrell CC, Tyler JK (2006) Hellebores. A comprehensive guide. Timber Press, Portland, OR, p 296

Cecchetti V, Altamura MM, Falasca G, Costantino P, Cardarelli M (2008) Auxin regulates Arabidopsis anther dehiscence, pollen maturation, and filament elongation. Plant Cell 20:1760-1774 
Cheng Y, Zhao Y (2007) A role for auxin in flower development. J Integr Plant Biol 49:99-104

Cohen JD, Bandurski RS (1982) Chemistry and physiology of the bound auxins. Annu Rev Plant Physiol 33:403-430

De Munk WJ (1979) Influence of plant growth regulators on the development of bulbous plants with special reference to organ relationship. Acta Hortic 91:207-219

Dettmer J, Elo A, Helariutta Y (2009) Hormone interactions during vascular development. Plant Mol Biol 69:347-360

Edelbluth E, Kaldewey H (1976) Auxin in scapes, flower buds, flower, and fruits of daffodil (Narcissus pseudonarcissus L.). Planta 131:285-291

Epstein E, Cohen JD, Slovin JP (2002) The biosynthetic pathway for indole-3-acetic acid changes during tomato fruit development. Plant Growth Regul 38:15-20

Finkelstein RR (2004) The role of hormones during seed development and germination. In: Davies PJ (ed) Plant hormones. Biosynthesis, signal transduction, action. Kluwer Academic Publishers, Dordrecht, pp 513-537

Gabryszewska E, Saniewski M (1983) Auxin control of tulip stalk elongation in vitro. Sci Hortic Amsterdam 19:153-159

Giannopolitis CN, Ries SK (1977) Superoxide dismutases. 1. Occurrence in higher plants. Plant Physiol 59:309-314

Guo Y, Yuan Z, Sun Y, Jing L, Huang H (2004) Characterizations of the uro mutant suggest that the URO gene is involved in the auxin action in Arabidopsis. Acta Bot Sin 46:846-853

Hangarter RP, Good NE (1981) Evidence that IAA conjugates are slow-release sources of free IAA in plant tissues. Plant Physiol 68:1424-1427

Hanks GR, Rees AR (1977) Stem elongation in tulip and narcissus: the influence of floral organs and growth regulators. New Phytol 78:579-591

Hess RJ, Carman JG, Banowetz GM (2002) Hormones in wheat kernels during embryony. J Plant Physiol 159:379-386

Ilić N, Magnus V, Ostin A, Sandberg G (1997) Stable-isotope labeled metabolites of the phytohormone, indole-3-acetic acid. J Label Compd Radiopharm 39:433-440

Jensen PJ, Bandurski RS (1994) Metabolism and synthesis of indole3-acetic acid (IAA) in Zea mays. Plant Physiol 106:343-351

Kai K, Horita J, Wakasa K, Miyagawa H (2007) Three oxidative metabolites of indole-3-acetic acid from Arabidopsis thaliana. Phytochemistry 68:1651-1663

Kohji J, Hagimoto H, Masuda Y (1979) Georeaction of the flower stalk in a poppy, Papaver rhoeas L. Plant Cell Physiol $20: 375-386$

Kowalczyk M, Sandberg G (2001) Quantitative analysis of indole-3acetic acid metabolites in Arabidopsis. Plant Physiol 127:1845-1853

Kumar N, Srivastava GC, Dixit K (2008) Senescence in rose (Rosa hybrida L.): role of the endogenous anti-oxidant system. J Hortic Sci Biotechnol 83:125-131

Laćan G, Magnus V, Šimaga Š, Iskrić S, Hall PJ (1985) Metabolism of tryptophol in higher and lower plants. Plant Physiol 78: $447-454$

Ljung K, Hull AK, Kowalczyk M, Marchant A, Celenza J, Cohen JD, Sandberg G (2002) Biosynthesis, conjugation, catabolism and homeostasis of indole-3-acetic acid in Arabidopsis thaliana. Plant Mol Biol 50:309-332

Ludwig-Müller J (2011) Auxin conjugates: their role for plant development and in the evolution of land plants. J Exp Bot 62:1757-1773

Ludwig-Müller J, Jülke S, Bierfreund NM, Decker EL, Reski R (2009) Moss (Physcomitrella patens) GH3 proteins act in auxin homeostasis. New Phytol 181:323-338

Magnus V, Ozga JA, Reinecke DM, Pierson GL, Larue TA, Cohen JD, Brenner ML (1997) 4-Chloroindole-3-acetic acid and indole3-acetic acid in Pisum sativum. Phytochemistry 46:675-681
Mathew B (1989) Hellebores. Alpine Garden Society, Lye End Link, St. John's Woking, Surrey, UK. $180 \mathrm{p}$

Maxwell K, Johnson N (2000) Chlorophyll fluorescence-a practical guide. J Exp Bot 51:659-668

Metcalfe CR, Chalk L (1972) Descriptions of the families 1. Ranunculaceae. In: Metcalfe CR, Chalk L (eds) Anatomy of the dicotyledons-leaves, stem and wood in relation to taxonomy with notes on economic uses, vol I. Clarendon Press, Oxford, pp 1-7

Mukherjee SP, Choudhuri MA (1983) Implications of water stressinduced changes in the levels of endogenous ascorbic-acid and hydrogen-peroxide in Vigna seedlings. Physiol Plant 58:166-170

Nakano Y, Asada K (1981) Hydrogen-peroxide is scavenged by ascorbate-specific peroxidase in spinach-chloroplasts. Plant Cell Physiol 22:867-880

Niewiadomska E, Polzien L, Desel C, Rozpadek P, Miszalski Z, Krupinska K (2009) Spatial patterns of senescence and development-dependent distribution of reactive oxygen species in tobacco (Nicotiana tabacum) leaves. J Plant Physiol 166: $1057-1068$

Nishio S, Moriguchi R, Ikeda H, Takahashi H, Takahashi H, Fujii N, Guilfoyle TJ, Kanahama K, Kanayama Y (2010) Expression analysis of auxin efflux carrier family in tomato fruit development. Planta 232:755-764

Normanly J (2010) Approaching cellular and molecular resolution of auxin biosynthesis and metabolism. Cold Spring Harb Perspect Biol 2:a001594

Ohno H, Kako S (1991) Roles of floral organs and phytohormones in flower stalk elongation of Cymbidium (Orhidaceae). J Jpn Soc Hortic Sci 60:159-169

Okubo H, Uemoto S (1985) Changes in endogenous gibberellin and auxin activities during 1st internode elongation in tulip flower stalk. Plant Cell Physiol 26:709-719

Op den Kelder P, Benschop M, De Hertogh AA (1971) Factors affecting floral stalk elongation of flowering tulips. J Am Soc Hortic Sci 96:603-605

Østergaard L (2009) Don't 'leaf' now. The making of a fruit. Curr Opin Plant Biol 12:36-41

Östin A, Moritz T, Sandberg G (1992) Liquid chromatography/mass spectrometry of conjugates and oxidative metabolites of indole3-acetic acid. Biol Mass Spectrom 21:292-298

Östin A, Kowalyczk M, Bhalerao RP, Sandberg G (1998) Metabolism of indole-3-acetic acid in Arabidopsis. Plant Physiol 118: 285-296

Ozga JA, Reinecke DM (2003) Hormonal interactions in fruit development. J Plant Growth Regul 22:73-81

Panavas T, Rubinstein B (1998) Oxidative events during programmed cell death of daylily (Hemerocallis hybrid) petals. Plant Sci 133:125-138

Pěnčík A, Rolčík J, Novák O, Magnus V, Barták P, Buchtík R, Salopek-Sondi B, Strnad M (2009) Isolation of novel indole-3acetic acid conjugates by immunoaffinity extraction. Talanta 80:651-655

Quittenden LJ, Davies NW, Smith JA, Molesworth PP, Tivendale ND, Ross JJ (2009) Auxin biosynthesis in pea: characterization of the tryptamine pathway. Plant Physiol 151:1130-1138

Rampey RA, LeClere S, Kowalczyk M, Ljung K, Sandberg G, Bartel B (2004) A family of auxin-conjugate hydrolases that contributes to free indole-3-acetic acid levels during Arabidopsis germination. Plant Physiol 135:978-988

Salopek-Sondi B, Magnus V (2007) Developmental studies in the Christmas rose (Helleborus niger L.). Int J Plant Dev Biol 1:151-159

Salopek-Sondi B, Kovač M, Ljubešić N, Magnus V (2000) Fruit initiation in Helleborus niger L. triggers chloroplast formation and photosynthesis in the perianth. J Plant Physiol 157:357-364 
Salopek-Sondi B, Kovač M, Prebeg T, Magnus V (2002) Developing fruit direct post-floral morphogenesis in Helleborus niger $\mathrm{L}$. J Exp Bot 53:1949-1957

Sancho MA, de Fochetti MS, Pliego F, Valpuesta V, Quesada MA (1996) Peroxidase activity and isoenzymes in the culture medium of $\mathrm{NaCl}$ adapted tomato suspension cells. Plant Cell Tissue Organ Cult 44:161-167

Saniewski M, De Munk WJ (1981) Hormonal control of shoot elongation in tulips. Sci Hortic 15:363-372

Schreiber U, Bilger W, Neubauer C (1994) Chlorophyll fluorescence as a nonintrusive indicator for rapid assessment of in vivo photosynthesis. In: Schulze ED, Caldwell MM (eds) Ecophysiology of photosynthesis. Ecological Studies, vol 100. SpringerVerlag, Berlin, pp 49-70

Siegel BZ, Galston AW (1967) Isoperoxidases of Pisum sativum. Plant Physiol 42:221-226

Srivastava A, Handa AK (2005) Hormonal regulation of tomato fruit development: a molecular perspective. J Plant Growth Regul 24:67-82

Sundberg E, Østergaard L (2009) Distinct and dynamic auxin activities during reproductive development. Cold Spring Harb Perspect Biol 1:a001628
Tam YY, Epstein E, Normanly J (2000) Characterization of auxin conjugates in Arabidopsis. Low steady-state levels of indole-3acetyl-aspartate, indole-3-acetyl-glutamate, and indole-3-acetylglucose. Plant Physiol 123:589-595

Tarkowski P, Tarkowská D, Novák O, Mihaljević S, Magnus V, Strnad M, Salopek-Sondi B (2006) Cytokinins in the perianth, carpels and developing fruit of Helleborus niger L. J Exp Bot 57:2237-2247

Wolbang CM, Chandler PM, Smith JJ, Ross JJ (2004) Auxin from the developing inflorescence is required for the biosynthesis of active gibberellins in barley stem. Plant Physiol 134:769-776

Xu RY, Niimi Y, Ohta Y (2008) Changes in diffusible indole-3-acetic acid from various parts of tulip plant during rapid elongation of the flower stalk. Plant Growth Regul 54:81-88

Yuan Z, Yao X, Zhang D, Sun Y, Huang H (2007) Genome-wide expression profiling in seedlings of the Arabidopsis mutant uro that is defective in the secondary cell wall formation. J Integr Plant Biol 49:1754-1762 